Received: 17 February 2017

Accepted: 8 January 2018

Published online: 24 January 2018

\section{Warming deferentially altered multidimensional soil legacy induced by past land use history}

Weiling Dong ${ }^{1,2}$, Alin Song ${ }^{2}$, Xueduan Liu' ${ }^{1}$, Bing Yu², Boren Wang ${ }^{2}$, Yuqiu Lu², Yanling Li², Huaqun Yin ${ }^{1}$, Jianwei $\mathrm{Li}^{3,4}$ \& Fenliang Fan ${ }^{2}$

The legacy effects of previous land use and climate history may affect current soil function. However, the manner in which these legacy effects of land use are modulated by the subsequent climate remains unclear. For this reason, we investigated how the legacies of soil multiple functions left by conversion of grassland to agricultural management were mediated by climate warming with a reciprocal transplant approach. The overall legacy was further separated into the contributions by changes in the abiotic properties of the soil (abiotic process) and microbial community (biotic process). We here hypothesized that warming may mediate the legacy effects of previous land use, mainly by changing biotic processes. Results indicated that warming significantly influenced the total legacies of soil respiration and three exoenzyme activities representing recalcitrant carbon, nitrogen, and phosphorus cycling, but did not affect the total legacy of $\beta$-1,4-glucosidase activity, which is involved in labile carbon cycling. The relative contributions of abiotic and biotic processes to the warming effects on the total legacy depended on the type of soil function. The effects of warming on land use change legacies were derived from altered bacterial community structure. The results of the present study suggest that climate conditions could interact with land use legacy to determine the ecosystem functions in a processspecific way.

Multifunction implemented by soil microbiome is essential to support the ecosystem services relevant to humanity, such as nutrients transformation, water cleaning, carbon sequestration ${ }^{1,2}$. A plethora of studies have documented that human activity significantly influences the soil biodiversity and function ${ }^{1}$. As the economy and environment change, some factors that originally affected the soil system cease to work or can be changed by other factors. For example, plough is abandoned to reduce soil erosion in slope farmland ${ }^{3}$ and monoculture is replaced by rotation to increase yield and nutrient use efficiency ${ }^{4}$. Some researchers have shown that the effect of the previous management by humans may persist, a phenomenon defined as a legacy effect ${ }^{5}$. There is a growing realization that legacy effects should be incorporated into current models to improve the predictability of soil functioning 6 .7.

The soil ecosystem is influenced by many factors besides previous and current human disturbances, including climate conditions. Seasonal temperature variation exceeds $10^{\circ} \mathrm{C}$ in most terrestrial biomes. Soil moisture produced by the precipitation can differ greatly across wet and dry seasons during the yearly cycle. In addition, the temperature and precipitation would be further shifted to different extents in different regions when global climate change ${ }^{8}$. These factors could change numerous soil chemical and biochemical reactions and shape soil microbial community, consequently changing the overall soil function ${ }^{9-11}$. Studies have shown that climate conditions themselves can leave legacy effects on soil function ${ }^{12}$. However, it is unclear how the climate conditions interact with the legacy effect induced by changes in land use on soil function ${ }^{13}$.

${ }^{1}$ Key Laboratory of Biometallurgy of Ministry of Education, School of Minerals Processing and Bioengineering, Central South University, Changsha, 410083, China. ${ }^{2}$ Key Laboratory of Plant Nutrition and Fertilizer, Ministry of Agriculture, Institute of Agricultural Resources and Regional Planning, Chinese Academy of Agricultural Sciences, Beijing, 100081, China. ${ }^{3}$ National Engineering Laboratory for Improving Quality of Arable Land, Institute of Agricultural Resources and Regional Planning, Chinese Academy of Agricultural Sciences, Beijing, 100081, China. ${ }^{4}$ Department of Agricultural and Environmental Sciences, Tennessee State University, Nashville, TN, 37209, USA. Correspondence and requests for materials should be addressed to H.Y. (email: yinhuaqun_cs@sina.com) or J.L. (email: jli2@tnstate.edu) or F.F. (email: fanfenliang@caas.cn) 
Previous studies of soil legacy can be categorized into three groups. First, only soil abiotic properties, such as $\mathrm{pH}$, cation exchange, and organic carbon, are affected by previous management history ${ }^{14,15}$. Second, only legacy induced by shift in the microbial community was monitored. For example, results showed that soil microbes from the home range (Europe) of the invasive exotic plant Centaurea maculosa L. have stronger inhibitory effects on its growth than soil microbes from where the weed has invaded in North America ${ }^{16}$. Third, these studies tended to investigate the overall legacy effect rather than examining abiotic and biotic components separately $y^{6,11,17}$. In most of these studies, only limited soil functions were investigated. It is largely unknown how legacy effects of multiple soil functions are left by previous soil management. The relative contributions of abiotic and biotic processes to the whole legacy effect are largely unclear ${ }^{18}$. It is also not clear whether changes in climate condition affect the legacy effects of land use by altering relative contribution of abiotic and biotic processes and that of the microbial community.

In order to support its large population, China has undergone intensive agriculture for a long time. The agricultural intensification has had significant undesirable influences on the soil system in many regions, such as soil acidification and erosion ${ }^{3,15}$. Therefore, it is urgent that more sustainable management practices, such as fallow, conversion of farmland to grassland, and hedgerow intercropping, should be adopted in these regions ${ }^{3,19}$. However, the manner in which these previous management practices will leave a legacy effect on soil function, especially under different climate conditions, is largely unclear. In the present study, we hypothesized that temperature mediates the legacy effects of previous land use majorly by changing biotic processes. Toward this end, the potential legacy effects of multiple soil processes induced by agricultural management at two temperatures $\left(15\right.$ and $\left.25^{\circ} \mathrm{C}\right)$ were explored with the reciprocal transplant approach in a hilly red soil of southern China, where the soil is subject to severe erosion ${ }^{20}$. The contributions of abiotic and biotic processes to the overall legacy effects were assessed, and soil microbial communities were investigated with next-generation sequencing.

\section{Results}

Soil function. Changes in abiotic properties, microbiomes, and temperature, and their interaction effects on soil respiration rates were all significant (Fig. 1A). Shifts from natural grassland soil (NAT) to agricultural soil (AGR) and increases in temperature (from 15 to $25^{\circ} \mathrm{C}$ ) enhanced soil respiration. Shifts from natural soil microbiome (nat) to agricultural soil microbiome (agr) did not change soil respiration at $15^{\circ} \mathrm{C}$, but they did reduce respiration in NAT at $25^{\circ} \mathrm{C}$ and increased respiration in AGR at $25^{\circ} \mathrm{C}$.

The overall effects of changing abiotic properties, microbiome, and temperature on acid phosphatase (AP) activity were all significant (Fig. 1B), but showing different patterns in AGR and NAT. In AGR, both shifts from nat to agr and increases in temperature increased AP activity. However, in NAT, the effects of shifts from nat to agr and increases in temperature on AP activity were not significant. Changing from NAT to AGR significantly reduced $\beta$-1,4-glucosidase ( $\beta G$ ) activity, and changes from nat to agr increased $\beta G$ activity. However, increases in temperature did not influence $\beta$ G activity (Fig. 1C). Leucine aminopeptidase (LAP) activity was determined principally by soil abiotic properties (Fig. 1D). LAP activity in AGR was 8 fold higher than in NAT. In addition, the overall effect of temperature was positive. LAP activity at $15^{\circ} \mathrm{C}$ and $25^{\circ} \mathrm{C}$ in NAT and at $25^{\circ} \mathrm{C}$ in AGR were higher with nat than with agr. The main effect of these changes on phenol oxide (PO) activity was only significant with respect to changes in soil abiotic properties (Fig. 1E).

Legacy of soil function. Agriculture had strong legacy effect on soil respiration and activities of the four exoenzymes (Fig. 2). The overall legacy effects on respiration (Fig. 2A), AP activity (Fig. 2B), and LAP activity (Fig. 2C) were positive, whereas the overall legacy effects on $\beta G$ (Fig. 2D) and PO activity (Fig. 2E) were negative. The abiotic and biotic components of legacy were also different for each individual soil function. The abiotic and biotic components of legacy effects on $\beta G$ activity had opposite effects. The total legacy effects of the soil respiration and the activity of the four exoenzymes, excepting AP, were majorly determined by abiotic processes associated with the legacy effect. However, the biotic processes associated with the legacy were also significant. In addition, changes in temperature significantly influenced total legacy of all the soil functions tested except for $\beta G$ activity. Furthermore, changes in temperature significantly influenced biotic process of the legacy on respiration, LAP, and PO activities and abiotic processes of the legacy effects on respiration.

Microbial abundance. Copy numbers of bacterial 16S rRNA gene in AGR was significantly higher than in NAT (Fig. 3A). Temperature and microbiome did not influence 16S rRNA gene abundance. Soil abiotic properties and microbiome significantly impacted copy numbers of fungal 18S rRNA gene, and their interactions were also significant (Fig. 3B). In NAT, copy numbers of fungal $18 \mathrm{~S}$ rRNA gene with nat were significantly higher than with agr, but the effect in AGR was not significant.

The total legacy on copy number of bacterial $16 \mathrm{~S}$ rRNA gene was positive (Fig. 4A). Abiotic process of the legacy on the copy number of bacterial 16S rRNA gene was similar to total legacy and higher than biotic process of the legacy. The total legacy on copy number of fungal $18 \mathrm{~S}$ rRNA gene was also positive (Fig. 4B). Abiotic and biotic processes of the legacy on the copy number of fungal $18 \mathrm{~S}$ rRNA gene were not significant.

Microbial community structure and composition. PCA analysis showed that soil bacterial community clustered according to soil abiotic properties and microbiome (Fig. 5A). The fungal community showed the same pattern as the bacterial community with a stronger temperature effect, but the effect of temperature on the bacterial community was relatively weak (Fig. 5B).

We also analyzed the legacy effects on the relative abundance of each bacterial and fungal order (Fig. 6). The results showed that the total legacy effects on the bacterial taxa had a continuously positive to negative range. The abiotic and biotic processes of the legacy effects on the bacterial taxa were also apparent, but the total legacy effects were more similar to abiotic component of the legacy. The overall effects of temperature shift on the relative 

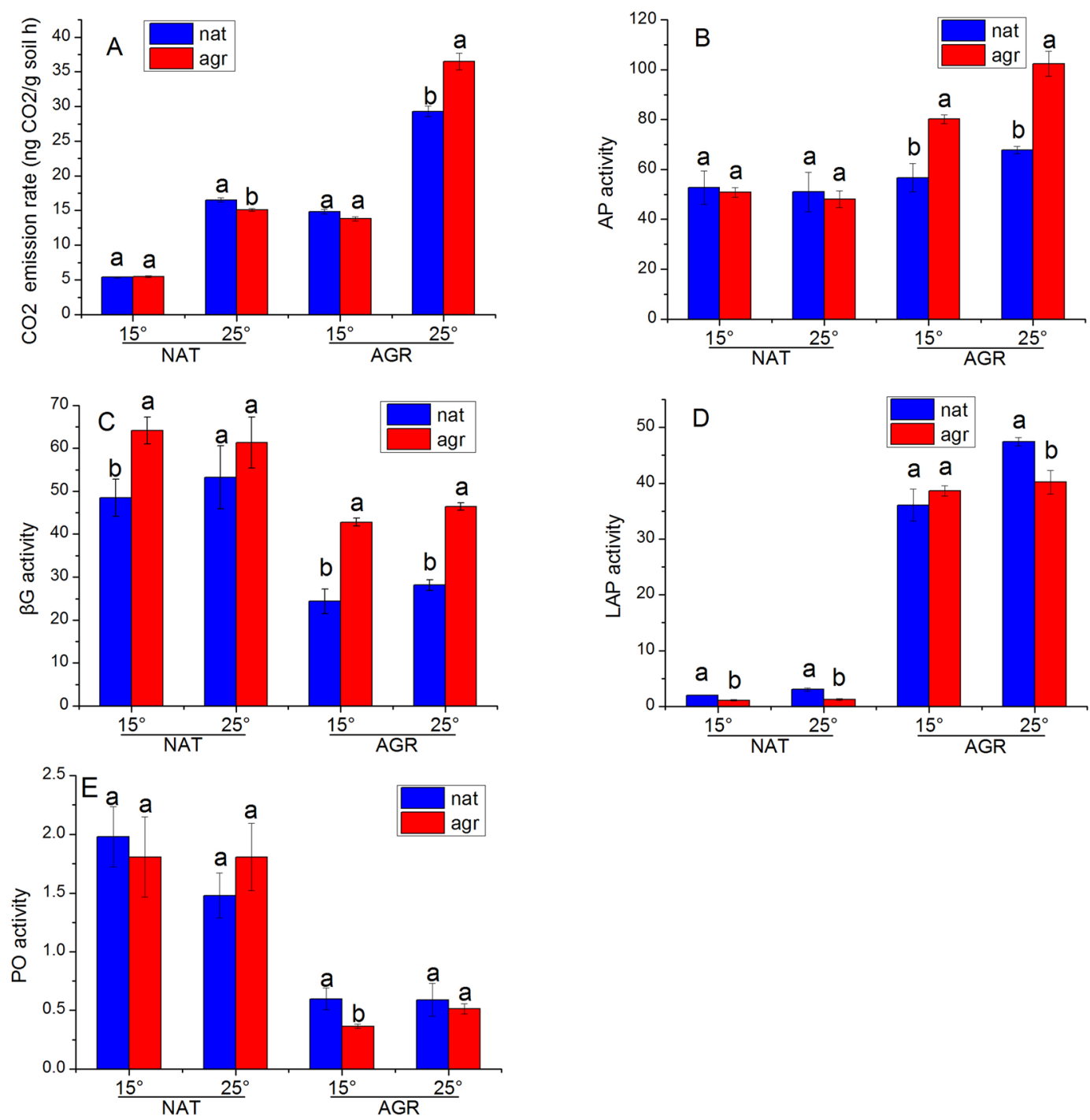

Figure 1. Soil microbial functions as affected by soil abiotic properties, microbiome and temperature. (A) Respiration; (B) acid phosphatase (AP); (C) $\beta$-1,4-glucosidase ( $\beta G) ;(D)$ leucine aminopeptidase (LAP) and (E) polyphenol oxidase (PO). Different letters indicate significant differences between microbiomes in each soil type-temperature combination. Error bars are standard error of the means with 5 replicates.

abundance of bacterial individual order were significant. Here, 48, 46, and 30 bacterial orders were significantly different at $15^{\circ} \mathrm{C}$ compared with $25^{\circ} \mathrm{C}$ for overall, abiotic, and biotic processes associated with the legacy effects, respectively. The total legacy effects on the relative abundance of fungal orders also showed a continuous positive to negative range, but the general patterns of abiotic and biotic processes of the legacy were different from those of the overall legacy effects (Fig. 7). In addition, the effect of temperature on the relative abundance of fungal orders was not significant.

\section{Discussion}

In the present study, we found that agricultural management with conventional fertilization left a strong legacy in soil multifunction in this soil (Figs 1 and 2), which is consistent with the detection of land use and climate change legacy targeting to single soil function ${ }^{7,10,21}$. Strikingly, warming significantly influenced the total legacies of four of the five soil functions examined here. These changes were produced by converting grassland to agricultural use. Our results expand the earlier findings that legacy of land use can be influenced by change in additional environmental condition ${ }^{7,18}$. As far as we know, this is the first study to show that warming may influence legacy effects of changes in land use, demonstrating that future climate conditions could interact with previous human activity to mediate ecosystem functioning.

The influences of warming on the multidimensional legacy of changes in land use are complex (Fig. 2). First, the direction of the influence was found to vary. For instance, warming increased the total legacy of AP activity and decreased the total legacies of respiration, LAP, and PO activity. However, warming did not change the total legacy of $\beta G$ activity. Second, the magnitudes of the warming effect on overall legacy effects were different for 

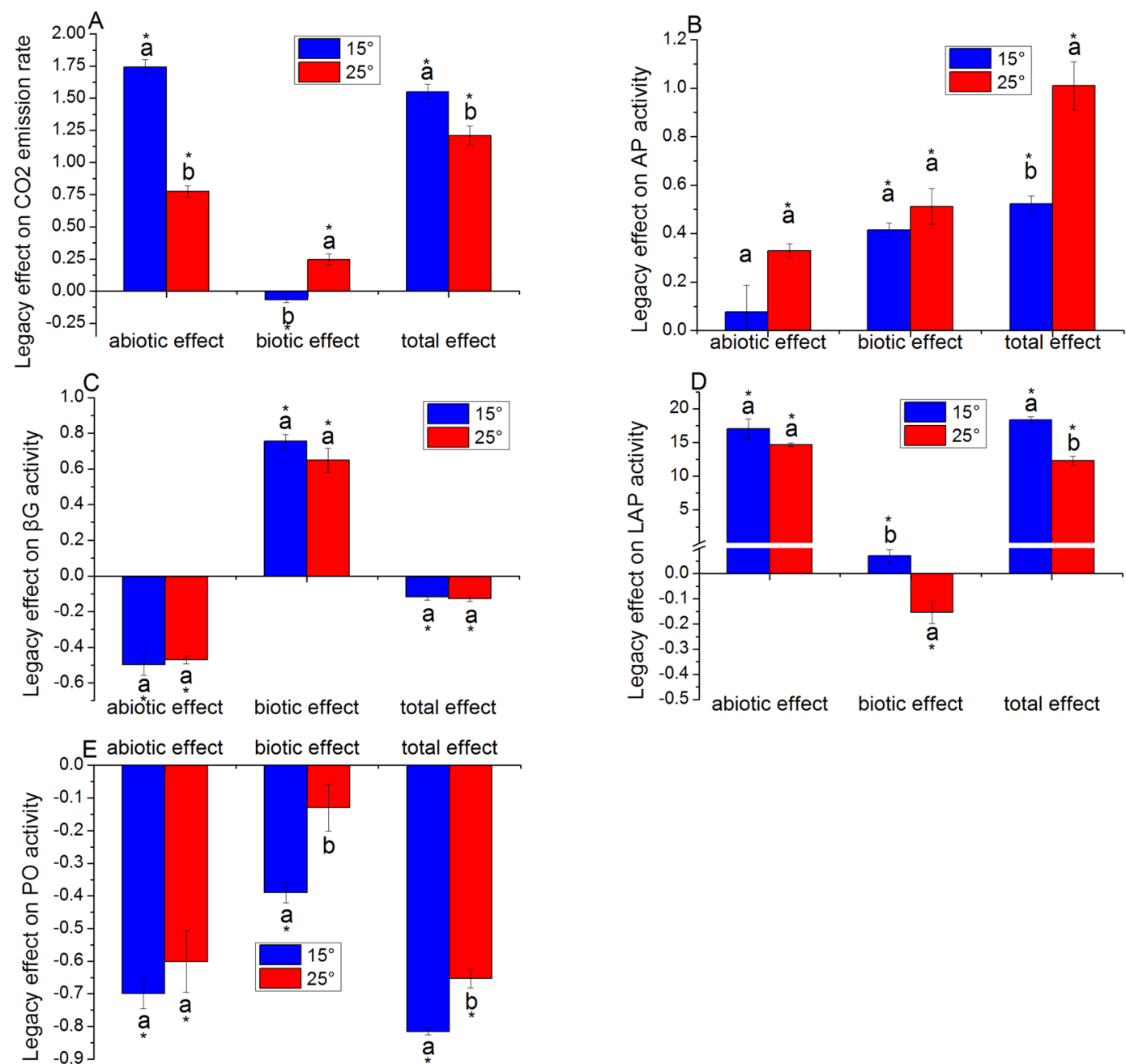

Figure 2. Abiotic and biotic process and total legacy effects on soil microbial functions at different temperatures. (A) Respiration; (B) acid phosphatase (AP); (C) $\beta$-1,4-glucosidase ( $\beta G$ ); (D) leucine aminopeptidase (LAP) and (E) polyphenol oxidase (PO). Different letters indicate significant differences between temperatures for each legacy type. *Indicate a significant difference from zero. Error bars are standard error of the means with 5 replicates.
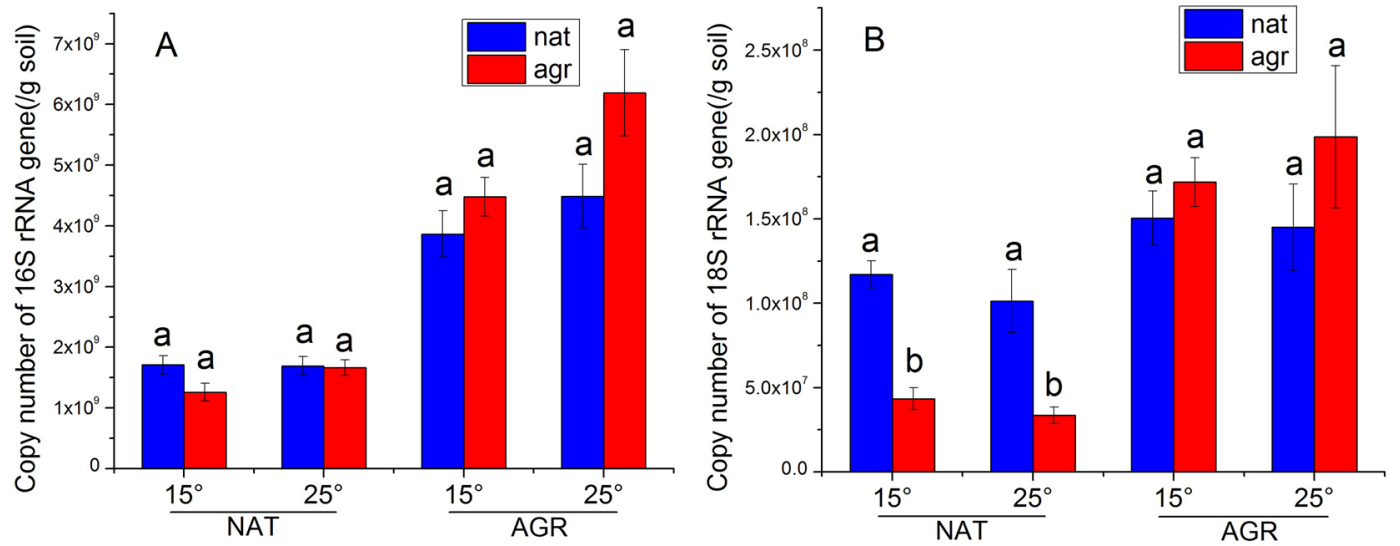

Figure 3. Microbial abundance as affected by soil abiotic properties, microbiome, and temperature. (A) Bacteria and (B) fungi. Different letters indicate significant differences between microbiomes in each soil typetemperature combination. Error bars are standard error of the means with 5 replicates. 
A

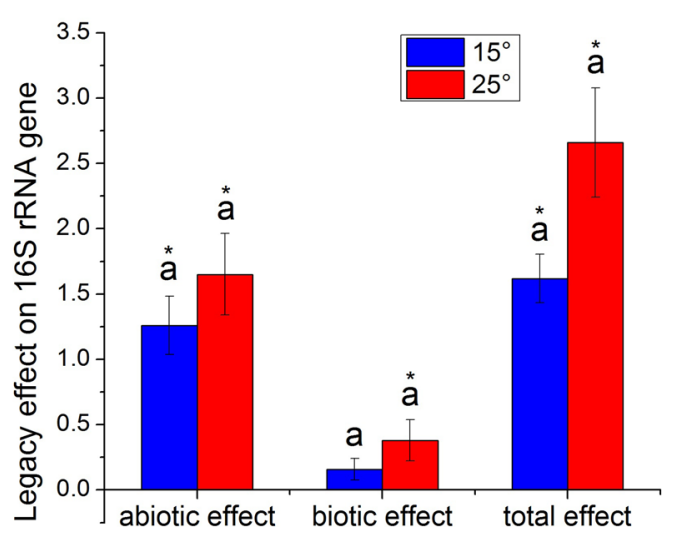

B

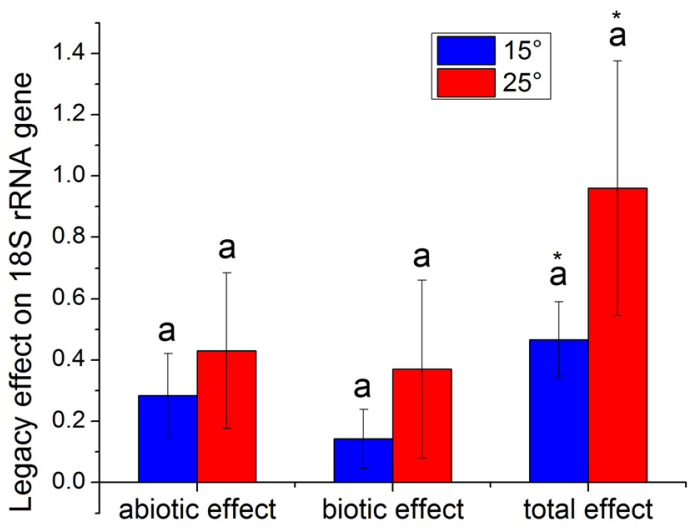

Figure 4. Abiotic and biotic processes and total legacy effects on microbial abundance at different temperatures. (A) Bacteria and (B) fungi. Different letters indicate significant differences between temperatures for each legacy type. *Indicate a significant difference from zero. Error bars are standard error of the means with 5 replicates.
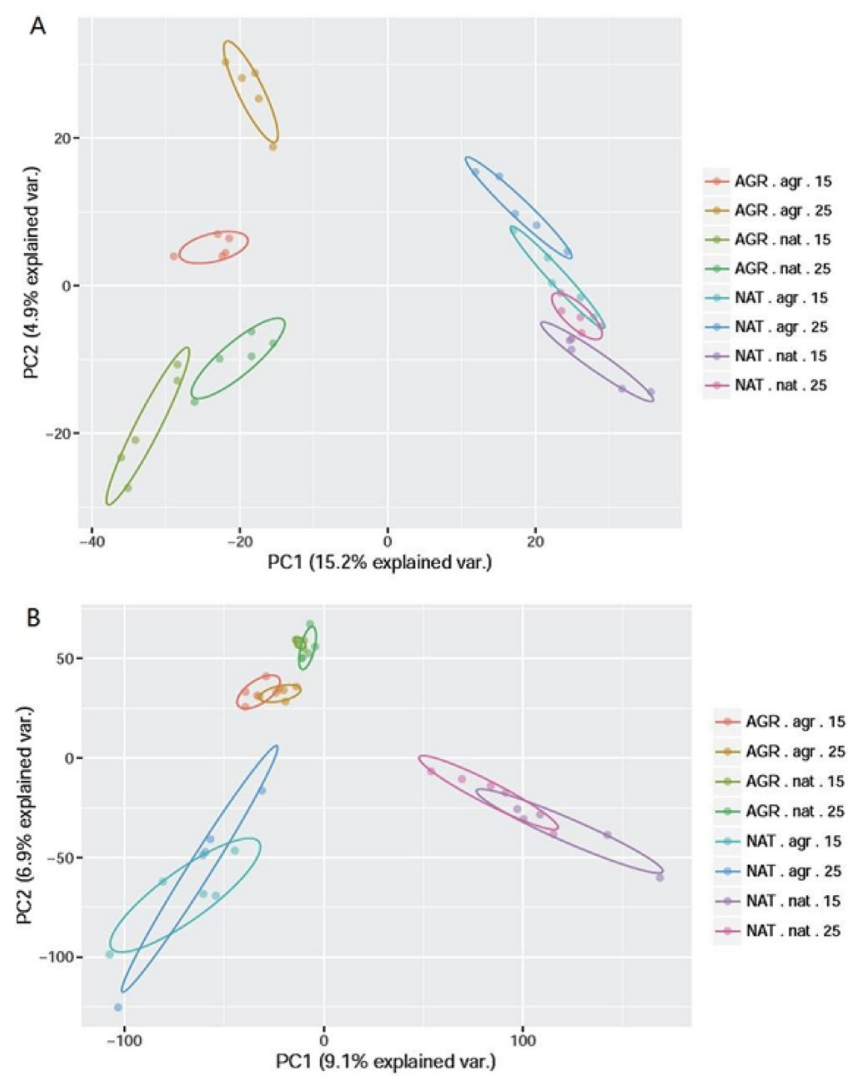

Figure 5. Principal component analysis of soil microbial community. (A) Bacteria and (B) fungi. AGR and NAT indicate agricultural and natural soils. agr and nat indicate microbiomes from AGR and NAT soils. 15 and 25 indicate 15 and 25 degrees Celsius $\left({ }^{\circ} \mathrm{C}\right)$, respectively.

different soil processes. They ranged from $0 \%$ for $\beta \mathrm{G}$ activity to $89 \%$ for AP activity. Third, the warming effect on the total legacies of the same type of soil function could be different. Warming decreased the total legacy of the activity of $\mathrm{PO}$, an exoenzyme degrading recalcitrant carbon, whereas it did not change the total legacy of the activity of $\beta G$, an exoenzyme that degrades labile carbon.

We then divided the overall legacy effects into abiotic and biotic processes. Results showed that the abiotic and biotic processes responded differently to warming. Warming only decreased the abiotic process of the legacy of respiration whereas had complex influences on biotic process of the legacies of the four soil functions. The 


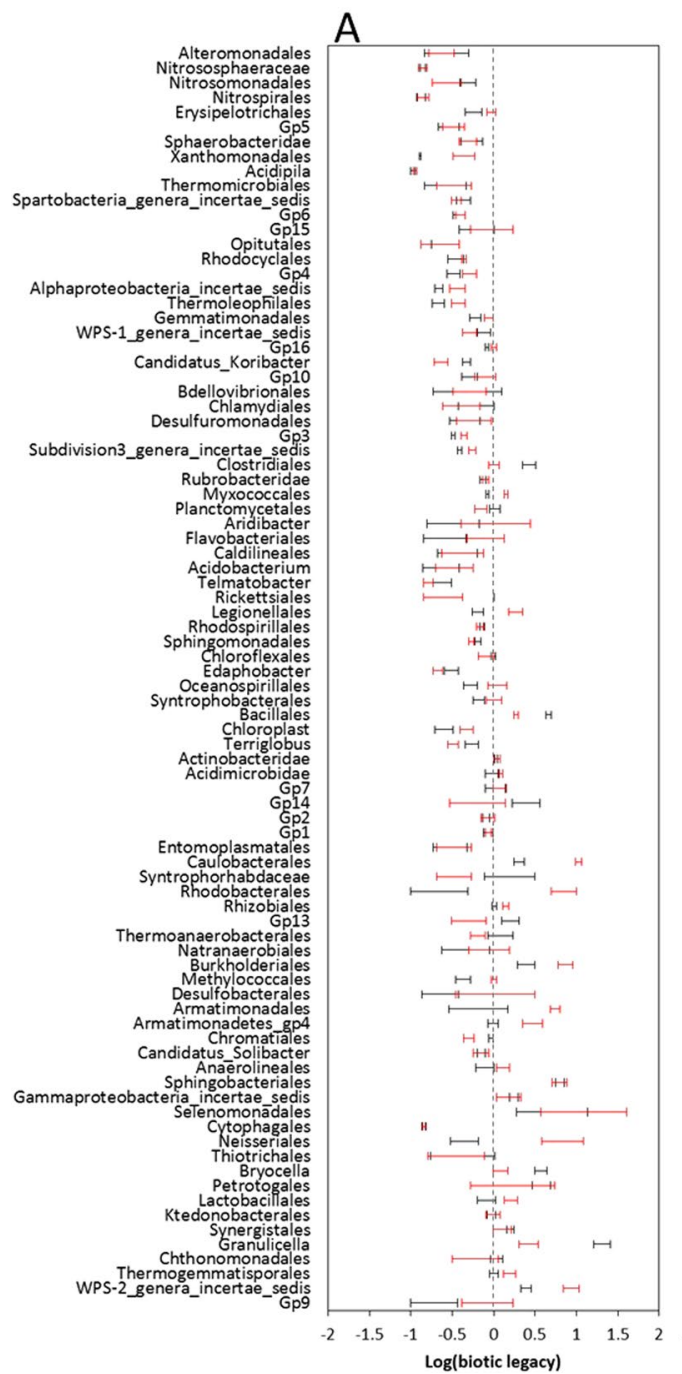

B

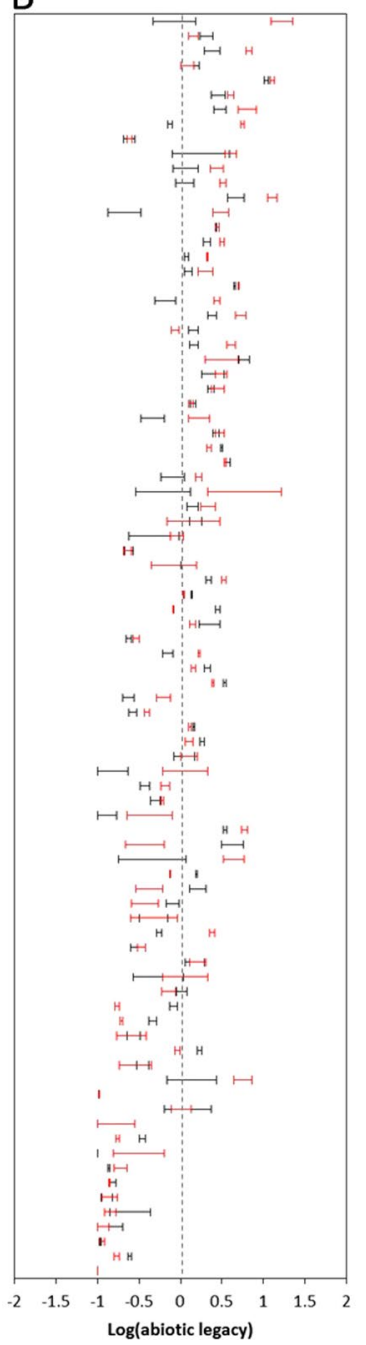

C

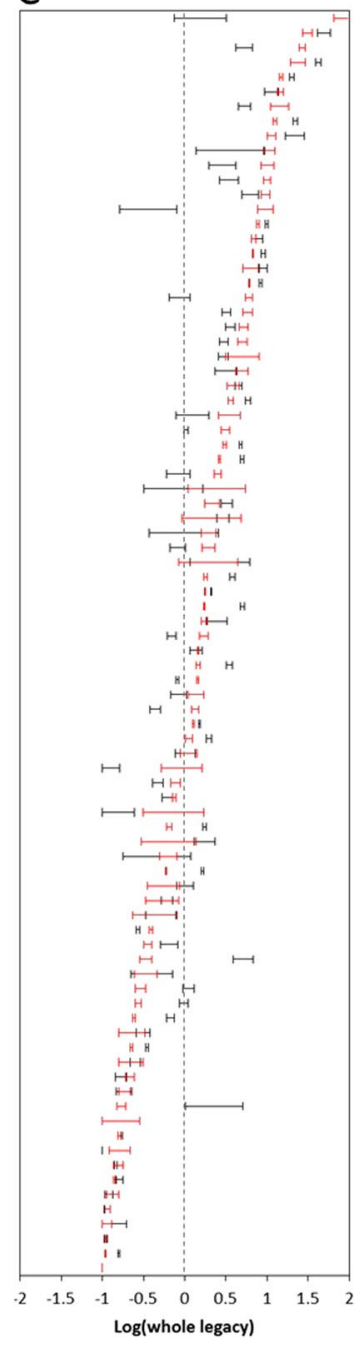

Figure 6. Abiotic and biotic processes and total legacy effects on relative abundance of each bacterial order at different temperatures. (A) Abiotic process; (B) biotic process; and (C) total legacy. Error bars are standard error of the means with 5 replicates. Black and red indicate 15 and 25 degrees Celsius $\left({ }^{\circ} \mathrm{C}\right)$, respectively.
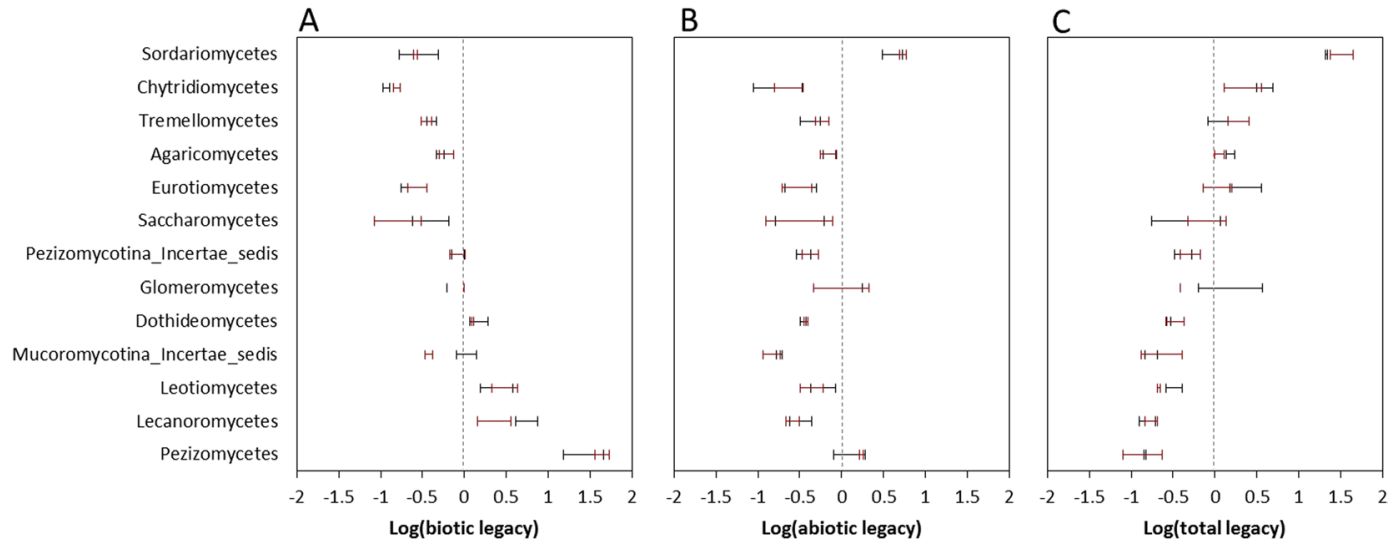

Figure 7. Abiotic and biotic processes and total legacy on relative abundance of each fungal order at different temperatures. (A) Abiotic process; (B) biotic process; and (C) total legacy. Error bars are standard error of the means with 5 replicates. Black and red indicate 15 and 25 degrees Celsius $\left({ }^{\circ} \mathrm{C}\right)$, respectively. 


\begin{tabular}{|l|c|c|}
\hline Soil properties & Natural soil & Agricultural soil \\
\hline $\mathrm{pH}(1: 1 \mathrm{w} / \mathrm{v}$ water $)$ & 4.23 & 5.70 \\
\hline Soil organic C $\left(\mathrm{g} \mathrm{kg}^{-1}\right)$ & 12.20 & 8.58 \\
\hline Total $\mathrm{N}\left(\mathrm{g} \mathrm{kg}^{-1}\right)$ & 2.10 & 1.07 \\
\hline Total $\mathrm{P}\left(\mathrm{g} \mathrm{kg}^{-1}\right)$ & 0.24 & 1.62 \\
\hline Available $\mathrm{P}\left(\mathrm{mg} \mathrm{kg}^{-1}\right)$ & 2.87 & 185.84 \\
\hline $\mathrm{NH}_{4}{ }^{+}$concentrations $\left(\mathrm{mg} \mathrm{kg}^{-1}\right)$ & 9.44 & 29.67 \\
\hline $\mathrm{NO}_{3}{ }^{-}$concentrations $\left(\mathrm{mg} \mathrm{kg}^{-1}\right)$ & 13.69 & 106.24 \\
\hline
\end{tabular}

Table 1. Basic soil properties of natural and agricultural soils at Qiyang site, southern China.

responses of overall legacy to warming seem to be an additive effect of warming responses of the abiotic and biotic processes. For instance, an intermediate reduction in the total legacy of respiration was the result of sharp reduction in abiotic process with complimentary increase in biotic process in response to warming. An additive of slight increase in abiotic and biotic processes contributed to a substantial enhancement of the total legacy of AP activity. This partly supported our hypothesis that temperature mediates the legacy induced by previous land use by changing biotic processes.

The differences in shift direction and extent of the legacies of different soil functions suggest that the mechanism is complex. The outcome of the interplay between different unknown mechanisms in response to warming may reflect in the alteration of microbiome, so we characterized the community with qPCR and high-throughput sequencing. The methods could not directly bridge the microbial identity with function but did have functional implications because the microbial function was phylogenetically conserved ${ }^{22,23}$. The response of legacy to warming was principally reflected in the community structure of bacteria but not in the abundance of bacteria or community structure and abundance of fungi (Figs 4 and 5). In addition, the different responses of legacies of different soil functions were found to correspond to positive changes, negative changes, and negligible changes in abundances of some bacterial orders but not fungal orders (Figs 6 and 7). The results suggest that the response of legacy effects to warming was principally derived from an altered bacterial community structure.

The present study has some limitations. First, the soil samples were collected once to test the warming effect on the land use legacy. The results obtained from a single test do not necessarily indicate an effect at other time as soil microbiome is seasonally variable. Second, we set the treatment temperature to approximately the annual average mean temperature, which may not reflect the situation during cold winters and hot summers. Third, we applied temperature treatment after land use had continued for over 50 years. These results reflected how the land use legacies could be realized under different climate conditions. Actually the temperature may exert its influence at all times when the land was used in different ways. All efforts to overcome these limitations would further improve the understanding of how climate change could interact with land use type to determine ecosystem functioning in the future.

In summary, we investigated the temperature response of legacies of soil multiple functions after the conversion of grassland to farmland via the reciprocal transplant approach. We found that the direction and magnitude of legacies differed across individual soil functions. We found that warming had strong influence on the land use legacy, through changing both abiotic and biotic processes. Microbiologically, the responses of land use legacies to warming were derived from altered bacterial communities. The results of the present study suggest that other environmental conditions would interact with soil legacy of changes in land use to determine the ecosystem functions in a process-specific way. These new findings should be incorporated into the previous knowledge frame on soil legacy induced by changes in land use or climate change separately.

\section{Methods}

Site description and soil sampling. The agricultural farmland soil (AGR) and natural soil (NAT) used for this incubation experiment were collected from Qiyang County $\left(26^{\circ} 45^{\prime} 12^{\prime \prime} \mathrm{N}, 111^{\circ} 52^{\prime} 32^{\prime \prime} \mathrm{E}\right)$, Hunan Province, southern China, after maize harvest at the end of August. The site has an average annual temperature and precipitation of $18^{\circ} \mathrm{C}$ and $1250 \mathrm{~mm}$, respectively. The soils are classified as ferralic cambisol and developed from quaternary red clay. The AGR and NAT samples were collected within $20 \mathrm{~m}$ of each other and were the same type of grassland about 50 years ago. AGR samples were collected from the conventional fertilization treatment in the long-term fertilization experiment of Chinese Academy of Agricultural Sciences which was previously described in detail ${ }^{24}$. Since 1990 , the nitrogen application rate of the treatment was $300 \mathrm{~kg} \mathrm{~N} \mathrm{hm}^{-2}$, with $70 \%$ from urea and $30 \%$ from pig manure $\mathrm{N}$. The application rates of $\mathrm{P}_{2} \mathrm{O}_{5}$ and $\mathrm{K}_{2} \mathrm{O}$ fertilizers are 120 and $120 \mathrm{~kg} \mathrm{ha}^{-1}$ year ${ }^{-1}$ in the form of calcium superphosphate and potassium chloride. The cropping system was a wheat-maize rotation cycle. NAT was collected from the grassland near the trial field used for the long-term fertilization experiment. The NAT had not ever been planted or supported a crop and its main vegetation was cogon grass (Imperata cylindrica). Soil was collected at several randomly chosen locations $(5 \mathrm{~cm}$ diameter $\times 20 \mathrm{~cm}$ depth $)$ and pooled to one composite sample to reduce heterogeneity. Fresh soil samples were first sieved at $2 \mathrm{~mm}$ and visible plant residues were removed by hand, adjusted to $60 \%$ water holding capacity, and stored in plastic bags. The soil properties of the two soils are listed in Table 1.

Experimental design. The two sets of soil samples (NAT and AGR) were sterilized with $40 \mathrm{kGy}$ gamma radiation. They were then inoculated with $7 \%$ of unsterilized AGR or NAT soil as a microbial inoculant (designated as agr and nat hereafter, respectively). In addition, 7\% either AGR or NAT unsterilized soil was added with 
the unsterilized soil to minimize amendment of extra amounts of nutrients. After homogenization, the bags were closed with sterilized cotton stoppers to prevent microbial contamination while allowing for air exchange. They were then stored at room temperature $\left(25 \pm 2{ }^{\circ} \mathrm{C}\right)$ in the dark for 4 weeks to allow microbial regeneration. After that, soil equivalent to $30 \mathrm{~g}$ dry mass was sealed in a $125 \mathrm{ml}$ serum bottles.

The experiment was carried out in a three-way random block design. The factors were as follows: temperature at two levels (defined as $15^{\circ} \mathrm{C}$ and $25^{\circ} \mathrm{C}$, hereafter), soils at two levels (AGR and NAT), and soil microbiome at two levels (agr and nat). Each treatment was performed in 5 replicates. Then the bottles were incubated at $15^{\circ} \mathrm{C}$ and $25^{\circ} \mathrm{C}$ for 20 days in the dark. The temperature was set around the average annual temperature of the site $\left(18^{\circ} \mathrm{C}\right)$ where the soils were collected. Gas samples $(10 \mathrm{ml})$ were taken from the headspace with a syringe at 2,5 , 10,15 , and 20 days after incubation. All bottles were ventilated for $5 \mathrm{~min}$ after gas was sampled, and the bottles were resealed. $\mathrm{CO}_{2}$ concentrations were measured with a gas chromatograph (HP7890A, Agilent Technologies, CA, US) as described by Fan et al. ${ }^{25}$. The bottles were destructively sampled at 20 days. Fresh soil samples were reserved for measurement of enzyme activity. The soil samples used for molecular analysis were stored at $-80^{\circ} \mathrm{C}$.

Measurements of soil exoenzyme activities. We measured four soil extracellular exoenzymes in the fresh soil. These enzymes are involved in carbon, nitrogen, and phosphorus cycling, including $\beta$-1,4-glucosidase $(\beta G)$, polyphenol oxidase (PO), leucine aminopeptidase (LAP), and acid phosphatase (AP). We chose these four exoenzymes because they are the rate limiting factors in organic matter degradation ${ }^{26-29}$ and the three elements are the major nutrients that influence plant growth, soil fertility, greenhouse gas emissions, and many other ecosystem functions ${ }^{24,30}$. Enzymes targeting labile and recalcitrant carbons were selected because the decomposition of labile and recalcitrant carbons respond differently to global climate change ${ }^{31}$. These four enzymes have been widely used as parameters to represent soil functions in other studies ${ }^{26,32-37}$.

The exoenzymes were measured with a micro-plate exoenzyme assay as described by Saiya-Cork et al. ${ }^{35}$. Briefly, soil suspension was pipetted into a 96-well black plate with a multichannel pipette and continuously homogenized with a magnetic stirrer during the process. The sample well was given $50 \mu \mathrm{L} 200 \mu \mathrm{mol} \cdot \mathrm{L}^{-1}$ substrate linked with 4-methylumbelliferyl (4-MUB) and $200 \mu \mathrm{L}$ soil suspension, the sample control well was given $50 \mu \mathrm{L}$ deionized water and $200 \mu \mathrm{L}$ soil suspension, the negative control well was given $50 \mu \mathrm{L}$ substrate and $200 \mu \mathrm{L}$ deionized water, the quench control well was given $50 \mu \mathrm{L}$ standard materials $\left(10 \mu \mathrm{mol} \mathrm{L}^{-1} 4-\mathrm{MUB}\right)$ and $200 \mu \mathrm{L}$ soil suspension, and the reference standard well was given $50 \mu \mathrm{L}$ standard materials and $200 \mu \mathrm{L}$ deionized water. The micro-plate was incubated at $25^{\circ} \mathrm{C}$ for $4 \mathrm{~h}$ in the dark, and then given $10 \mu \mathrm{L}$ of $0.5 \mathrm{M} \mathrm{NaOH}$ to terminate the reaction. Fluorescence was measured with $365 \mathrm{~nm}$ excitation and $450 \mathrm{~nm}$ emission filters using a microplate fluorometer.

DNA extraction and real-time quantitative PCR (qPCR). DNA extraction was performed using FastDNA spin kit for soil (MP Biomedicals) in accordance with the manufacturer's instructions. The $0.5 \mathrm{~g}$ soil samples were prepared for DNA extraction to acquire enough DNA for subsequent testing. The extracted DNA was electrophoresed on $1.0 \%$ agarose gel and measured concentration using Nanodrop 2000 spectrophotometer (Thermo Scientific).

We performed qPCR assays to determine the abundance of DNA within the different samples. We used an ABI prism 7900 (Applied Biosystems) machine and SYBR green to quantify bacterial and fungal DNA obtained with primers that targeted regions of the $16 \mathrm{~S}$ rRNA and $18 \mathrm{~S}$ rRNA gene. For bacterial qPCR, each $15 \mu \mathrm{L}$ reaction mixture contained the following: $7.5 \mu \mathrm{L}$ of SYBR Premix Ex Taq (TaKaRa); 0.3 $\mu \mathrm{L}$ Rox (TaKaRa); $0.3 \mu \mathrm{L}$ forward primer $357 \mathrm{~F}$ and $0.3 \mu \mathrm{L}$ reverse primer $518 \mathrm{R}$; $4.6 \mu \mathrm{L}$ pure $\mathrm{H}_{2} \mathrm{O}$; and $2 \mu \mathrm{L}$ DNA template. For fungal qPCR, each $15 \mu \mathrm{L}$ reaction mixture contained the following: $7.5 \mu \mathrm{L}$ of SYBR Premix Ex Taq (TaKaRa); 0.3 $\mu \mathrm{L}$ Rox (TaKaRa); $0.3 \mu \mathrm{L}$ forward primer FF390, and $0.3 \mu \mathrm{L}$ of reverse primer FR1. The primer pairs were tested and these PCR amplicons were used to generate a set of standards with known copy numbers of the target sequence. Standards were created by performing a 1:10 serial dilution to achieve a range from 10 to $10^{8}$ copies of the $16 \mathrm{~S}$ rRNA or $18 \mathrm{~S}$ rRNA gene. The coefficients of determination $\left(\mathrm{r}^{2}\right)$ for our assays were 0.999 and 0.996 for the bacterial and fungal qPCR, respectively. The thermal cycle protocol was as follows: $95^{\circ} \mathrm{C}$ at $3 \mathrm{~min}$, followed by 40 cycles of $10 \mathrm{~s}$ at $95^{\circ} \mathrm{C}$, $30 \mathrm{~s}$ at $52^{\circ} \mathrm{C}$, and $45 \mathrm{~s}$ at $72{ }^{\circ} \mathrm{C}$, with a $10 \mathrm{~min}$ final extension at $72^{\circ} \mathrm{C}$.

Ion torrent sequencing. DNAs for microbial community determination were diluted to $2 \mathrm{ng} \mu \mathrm{l}^{-1}$. $16 \mathrm{~S}$ RNA genes in the DNAs were amplified with primers $515 \mathrm{f}$ and $806 \mathrm{r}$ (Peiffer et al. 2013) with a $12 \mathrm{bp}$ barcode attached to the $5^{\prime}$ end of the reverse primer. Fungal internal transcribed spacer (ITS) regions were amplified with primers ITS 3 and ITS 4 with a unique $12 \mathrm{bp}$ barcode attached to the $5^{\prime}$ end of primer ITS3. The $25 \mu \mathrm{l}$ PCR mixture contained $2 \mu \mathrm{l}$ template DNA, $2 \mu \mathrm{l}$ dNTP, $0.5 \mu \mathrm{l}$ forward and reverse primers, $0.25 \mu \mathrm{l} \mathrm{rTaq}$ (Takara), $2.5 \mu \mathrm{l} 10 \times \mathrm{rTaq}$ buffer and $16.75 \mu \mathrm{l}$ molecular biology grade water. All reactions were performed in triplicates using Biorad PCR machine (PTC 200, Biorad) with initial $94^{\circ} \mathrm{C}$ denaturation for 4 min followed by 25 cycles of denaturing in $94^{\circ} \mathrm{C}$ for $1 \mathrm{~min}, 55^{\circ} \mathrm{C}$ annealing for $1 \mathrm{~min}$, and $72^{\circ} \mathrm{C}$ extension for $2 \mathrm{~min}$ with a final extension at $72^{\circ} \mathrm{C}$ for $10 \mathrm{~min}$. Equal mole of amplicons were pooled and gel purified with PCR amplicons purification kit (Tiangen Technologies). A library was constructed using an Ion Plus Fragment Library Kit and Ion PGM Template OT2 400 Kit and subsequently sequenced with an Ion PGM Sequencing 400 Kit and Ion 318TM Chip Kit v2 on an Ion Torrent PGM machine (Life Technologies).

Sequences with quality scores greater than 20 and without mismatches between the barcode and primer were processed further. The sequences were trimmed to $200 \mathrm{bp}$ before clustering with UPARSE at a $97 \%$ similarity level ${ }^{38}$. Chimeras in the sequences were filtered with $\mathrm{UCHIME}^{39}$. The sequences analysis was performed using the USEARCH package ${ }^{40}$. Representative sequences were classified on RDP pipeline (http://pyro.cme.msu.edu/). An OTU table was rarefied to 2891 and 540 sequences per sample for $16 \mathrm{~S}$ and ITS, respectively. The sequences were deposited in National Center for Biotechnology Information (NCBI) Sequence Read Archive (SRA) under accession number SRP074820. 
Statistical analysis. Total legacy was calculated as the relative change ratio of an individual function induced by the shifts in both soil abiotic properties and the microbiome as reported previously ${ }^{12,13}$. Abiotic processes associated with the legacy effects were calculated as the relative change ratio of an individual function induced by abiotic properties of soil samples inoculated with the same microbiome. Biotic process of the legacy was calculated as the relative change ratio of an individual function induced by inoculation of different microbiomes in the same sterilized soil. The calculation formulas were as follows:

$$
\begin{aligned}
& \text { Abiotic effect }=(\text { AGR with nat }- \text { NAT with nat }) / \text { NAT with nat } \\
& \text { Biotic effect }=(\text { AGR with agr }- \text { AGR with nat }) / A G R \text { with nat } \\
& \text { Total effect }=(\text { AGR with agr }- \text { NAT with nat }) / N A T \text { with nat }
\end{aligned}
$$

A three-way analysis of variance (ANOVA) was used to determine the effects of soil type, microbiome, and temperature on respiration, exoenzyme activity, and microbial community properties with SAS Windows version 9.1 (SAS Institute Inc., US). Principal component analysis (PCA) ordination of the relative abundances of OTUs detected in each sample was performed using a vegan package ${ }^{41}$ in an $\mathrm{R}$ statistics environment ${ }^{42}$. To examine the association of microbial community structure with function, the correlation between microbial community structure and soil functions was analyzed using Mantel test with the vegan package.

\section{References}

1. Bardgett, R. D. \& van der Putten, W. H. Belowground biodiversity and ecosystem functioning. Nature 515, 505-511 (2014).

2. Wall, D. H., Nielsen, U. N. \& Six, J. Soil biodiversity and human health. Nature. https://doi.org/10.1038/nature15744 (2015).

3. Fu, B. Soil erosion and its control in the Loess Plateau of China. Soil Use and Management 5, 76-82 (1989).

4. Fan, F. et al. Nitrogen fixation of faba bean (Vicia faba L.) interacting with a non-legume in two contrasting intercropping systems. Plant and Soil 283, 275-286 (2006).

5. Cuddington, K. Legacy effects: the persistent impact of ecological interactions. Biological Theory 6, 203-210 (2011).

6. Marschner, P., Hatam, Z. \& Cavagnaro, T. R. Soil respiration, microbial biomass and nutrient availability after the second amendment are influenced by legacy effects of prior residue addition. Soil Biology and Biochemistry 88, 169-177, https://doi. org/10.1016/j.soilbio.2015.05.023 (2015).

7. Foster, D. et al. The importance of land-use legacies to ecology and conservation. BioScience 53, 77-88 (2003).

8. Meehl, G. A. et al. In Climate Change 2007: The Physical Science Basis. Contribution of Working Group I to the Fourth Assessment Report of the Intergovernmental Panel on Climate Change Vol. 3495 (ed S. Solomon, D. Qin, M. Manning, Z. Chen, M. Marquis, K. B. Averyt, M. Tignor and H. L. Miller) 747-845 (Cambridge University Press, 2007).

9. Zhou, J.et al. Microbial mediation of carbon-cycle feedbacks to climate warming. Nature Climate Change 2, 106-110 (2012).

10. Banerjee, S. et al. Legacy effects of soil moisture on microbial community structure and N2O emissions. Soil Biology and Biochemistry 95, 40-50 (2016).

11. Cavagnaro, T. R. Soil moisture legacy effects: Impacts on soil nutrients, plants and mycorrhizal responsiveness. Soil Biology and Biochemistry 95, 173-179 (2016).

12. Meisner, A., De Deyn, G. B., de Boer, W. \& van der Putten, W. H. Soil biotic legacy effects of extreme weather events influence plant invasiveness. Proceedings of the National Academy of Sciences 110, 9835-9838 (2013).

13. Li, J., Ziegler, S. E., Lane, C. S. \& Billings, S. A. Legacies of native climate regime govern responses of boreal soil microbes to litter stoichiometry and temperature. Soil Biology and Biochemistry 66, 204-213, https://doi.org/10.1016/j.soilbio.2013.07.018 (2013).

14. Ward, S. E. et al. Legacy effects of grassland management on soil carbon to depth. Global change biology (2016).

15. Guo, J. et al. Significant acidification in major Chinese croplands. science 327, 1008-1010 (2010).

16. Callaway, R. M., Thelen, G. C., Rodriguez, A. \& Holben, W. E. Soil biota and exotic plant invasion. Nature 427, 731-733 (2004).

17. Elgersma, K. J., Ehrenfeld, J. G., Yu, S. \& Vor, T. Legacy effects overwhelm the short-term effects of exotic plant invasion and restoration on soil microbial community structure, enzyme activities, and nitrogen cycling. Oecologia 167, 733-745 (2011).

18. Martiny, J. B. et al. Microbial legacies alter decomposition in response to simulated global change. The ISME journal (2016).

19. Sun, H., Tang, Y. \& Xie, J. Contour hedgerow intercropping in the mountains of China: a review. Agroforestry systems 73, 65-76 (2008).

20. Liang, Y. et al. Soil erosion changes over the past five decades in the red soil region of southern China. Journal of Mountain Science 7, 92-99 (2010).

21. Zuppinger-Dingley, D., Flynn, D. F., De Deyn, G. B., Petermann, J. S. \& Schmid, B. Plant selection and soil legacy enhance long-term biodiversity effects. Ecology $97,918-928$ (2016).

22. Martiny, A. C., Treseder, K. \& Pusch, G. Phylogenetic conservatism of functional traits in microorganisms. The ISME journal 7, 830-838 (2013).

23. Morrissey, E. M. et al. Phylogenetic organization of bacterial activity. The ISME journal (2016).

24. Zhang, W., Xu, M., Wang, B. \& Wang, X. Soil organic carbon, total nitrogen and grain yields under long-term fertilizations in the upland red soil of southern China. Nutrient Cycling in Agroecosystems 84, 59-69 (2009).

25. Fan, F. et al. Probing potential microbial coupling of carbon and nitrogen cycling during decomposition of maize residue by 13 C-DNA-SIP. Soil Biology and Biochemistry 70, 12-21 (2014).

26. Sinsabaugh, R. L. et al. Stoichiometry of soil enzyme activity at global scale. Ecology letters 11, 1252-1264 (2008).

27. Dilly, O. \& Nannipieri, P. Response of ATP content, respiration rate and enzyme activities in an arable and a forest soil to nutrient additions. Biology and Fertility of Soils 34, 64-72, https://doi.org/10.1007/s003740100375 (2001).

28. Gong, C. S. \& Tsao, G. T. Cellulase and biosynthesis regulation. Annual Reports on Fermentation Processes 3, 111-140 (1979).

29. Sinsabaugh, R. L. Phenol oxidase, peroxidase and organic matter dynamics of soil. Soil Biol. Biochem. 42, 391-404, https://doi. org/10.1016/j.soilbio.2009.10.014 (2010).

30. Fan, F., Li, Z., Wakelin, S. A., Yu, W. \& Liang, Y. Mineral fertilizer alters cellulolytic community structure and suppresses soil cellobiohydrolase activity in a long term fertilization experiment. Soil Biology and Biochemistry 55, 70-77 (2012).

31. Davidson, E. A. \& Janssens, I. A. Temperature sensitivity of soil carbon decomposition and feedbacks to climate change. Nature 440 , 165-173 (2006).

32. Caldwell, B. A. Enzyme activities as a component of soil biodiversity: A review. Pedobiologia 49, 637-644, https://doi.org/10.1016/j. pedobi.2005.06.003 (2005).

33. Allison, S. D. \& Treseder, K. K. Warming and drying suppress microbial activity and carbon cycling in boreal forest soils. Global Change Biology 14, 2898-2909, https://doi.org/10.1111/j.1365-2486.2008.01716.x (2008). 
34. Zhou, X. et al. Warming and increased precipitation have differential effects on soil extracellular enzyme activities in a temperate grassland. Sci Total Environ 444, 552-558, https://doi.org/10.1016/j.scitotenv.2012.12.023 (2013).

35. Saiya-Cork, K. R., Sinsabaugh, R. L. \& Zak, D. R. The effects of long term nitrogen deposition on extracellular enzyme activity in an Acer saccharum forest soil. Soil Biology and Biochemistry 34, 1309-1315 (2002).

36. Wallenstein, M. D., McMahon, S. K. \& Schimel, J. P. Seasonal variation in enzyme activities and temperature sensitivities in Arctic tundra soils. Global Change Biology 15, 1631-1639, https://doi.org/10.1111/j.1365-2486.2008.01819.x (2009).

37. Liu, S. et al. Spatio-temporal patterns of enzyme activities after manure application reflect mechanisms of niche differentiation between plants and microorganisms. Soil Biol. Biochem. 112, 100-109, https://doi.org/10.1016/j.soilbio.2017.05.006 (2017).

38. Edgar, R. C. UPARSE: highly accurate OTU sequences from microbial amplicon reads. Nature methods 10, 996-998 (2013).

39. Edgar, R. C., Haas, B. J., Clemente, J. C., Quince, C. \& Knight, R. UCHIME improves sensitivity and speed of chimera detection. Bioinformatics 27, 2194-2200 (2011).

40. Edgar, R. C. Search and clustering orders of magnitude faster than BLAST. Bioinformatics 26, 2460-2461 (2010).

41. Oksanen, J. et al. The vegan package. Community ecology package, 631-637 (2007).

42. Team, R. D. C. R: A Language and Environment for Statistical Computing. R Foundation for Statistical Computing, Vienna, Austria, http://www.R-project.org/ (2014).

\section{Acknowledgements}

This work was jointly supported by National Natural Science Foundation of China $(41571297,41471248)$. The National Key Research and Development Program of China (2016YFD0200109). The National Basic State Basic Research Program of China (2014CB441001). USDA Evans-Allen grant awarded to JL (No. 1005761) and National Nonprofit Institute Research Grant of CAAS (IARRP-2014-29 and IARRP-2015-20).

\section{Author Contributions}

W.D., H.Y. and F.F. conceived and designed the experiments. W.D., A.S., B.Y., B.W., Y.L., Y.L. and F.F. performed the experiments. W.D., X.L., H.Y., J.L. and F.F. analyzed the data. W.D., H.Y., J.L. and F.F. wrote the manuscript. All authors read and approved the final manuscript.

\section{Additional Information}

Competing Interests: The authors declare that they have no competing interests.

Publisher's note: Springer Nature remains neutral with regard to jurisdictional claims in published maps and institutional affiliations.

(c) (i) Open Access This article is licensed under a Creative Commons Attribution 4.0 International License, which permits use, sharing, adaptation, distribution and reproduction in any medium or format, as long as you give appropriate credit to the original author(s) and the source, provide a link to the Creative Commons license, and indicate if changes were made. The images or other third party material in this article are included in the article's Creative Commons license, unless indicated otherwise in a credit line to the material. If material is not included in the article's Creative Commons license and your intended use is not permitted by statutory regulation or exceeds the permitted use, you will need to obtain permission directly from the copyright holder. To view a copy of this license, visit http://creativecommons.org/licenses/by/4.0/.

(C) The Author(s) 2018 